\title{
LIE IN MARK HADDON'S NOVEL THE CURIOUS INCIDENT OF THE DOG IN THE NIGHT-TIME
}

\author{
Fadil Muhammad, Pardi \\ Faculty of Literature, Universitas Islam Sumatera Utara, Medan \\ e-mail: mhdfadhil787@gmail.com
}

\begin{abstract}
This research aims to analyze lie and types of lie in Mark Haddon's novel entitled The Curious Incident of The Dog in the Night-Time. The fifteen-year-old narrator of the story, Christopher John Francis Boone discovers the slain body of his neighbor's Poodle Wellington, on the neighbor front lawn, one evening and sets out to uncover the murderer. His investigation is at times aided, and at other times hampered, by the mild form of Autism he lives with. Christopher has a certain character. He finds difficulty in his social interaction; be it in his appearance, language attitude, or thinking. In addition, Christopher has an intelligent ability. He is able to interpret objects around him well. The novel ends with Christopher planning to take A-level exams in physics and further math, and then attend a university in another town. The method of the data analysis in this research uses descriptive qualitative method, and the theory applied in this research was following Bryant (2008) who divided lie into 3 types, i.e. real lies, white lies, and gray lies. The research result shows that all the three types of lie proposed by Bryant are vividly reflected by Christopher in the novel.
\end{abstract}

Keywords: Characteristic, Lie, Types of Lie,

\section{Introduction}

The Curious Incident of the Dog in the Night-time written by Mark Haddon takes place in the year 1998 in and around the town of Swindon, England. The fifteen-year-old narrator of the story, Christopher John Francis Boone, discovers the slain body of his neighbor's poodle, Wellington, on the neighbor's front lawn one evening and sets out to uncover the murderer. His investigation is at times aided, and at other times hampered, by the mild form of autism he lives with. After Christopher hits a policeman in a misunderstanding at the scene of the crime, the police take Christopher into custody. They release Christopher with only a stern warning, under the condition that he promises to them and to his father not to look into the murder any further.

There is no universally agreed upon definition of lying. It is commonly agreed that, as contrasted with the verb 'deceive,' which is a success or achievement verb like 'persuade' or 'cure,' the verb 'lie' is not a success or achievement verb. The speech act of lying is not an elocutionary speech act. That is, whether or not an act of lying has occurred does not depend on whether a particular effect, such as a false belief, has been produced. A lie that is 'seen through' by its audience while it is being told to them, and 
hence, that does not deceive them, is still a lie. Properly speaking, therefore, lying is not a type of deceiving. Beyond this, there is little consensus on defining lying. Although most hold that lying requires that one make a statement, some hold that merely acting in an intentionally deceptive way is lying. On this view, for example, faking a limp is lying. Some even hold that simply remaining silent, with a deceptive intention, is a 'lie of omission.' Although most hold that lying requires that one make a statement that one believes to be false (an untruthful statement), some hold that it is possible to lie by making a statement that one believes to be true (a truthful statement), so long as this is done with a deceptive intention. Although most hold that in order to lie one must be addressing someone, some hold that it is possible to lie to eavesdroppers. Some even hold that it is possible to lie to no one at all, not even oneself that, for instance, simply making untruthful statements in an empty room can be lying.

\section{Literature Review}

Lying is a behavior that seems common throughout various cultures, ages, settings, and more. Lying also seems to be associated with several societal problems; it often disrupts social relationships, causes problems in the workplace, and corrupts politics, for examples. Most often, however, individuals who engage in lying behavior are considered to be liars, whereby the problem of lying is considered to reside within the individual. Following from this, the individual is to be held responsible for their lying behavior. In this sense, a consideration of environmental factors that lead to the development and persistence of lying is bypassed, as the problem of lying is assumed to reside within the individual (Fryling, 2016: 13).

\subsection{The Structure of a Lie}

Lies and truths also differ in the way in which they are constructed. It is often the case that more than one possible lies is available. In this case the particular lie produced needs to be explicitly chosen from a range of alternatives. For a lie to be convincing then it must be plausible and consistent with previous information and so selecting such a lie introduces additional constraints. Truths, on the other hand, seem to be generated automatically without a need to always select "which" truth, since stimulus questions must merely be evaluated in relation to known information. The procedures needed to choose which lie to use and to verify the plausibility may be costly to operate. (Boaz TL, Perry NW, Raney G, Fischler IS, Schuman D in Williams, et.al, 2013: 2)

Like all humans, lies determine many things (Waelder in Akhtar \& Parens, 2009). Every lie is an instinctual pressure, narcissistic interest, superego disability, and ego weakness. Every lie is a fantasy of my imagination and an attempt towards a feared imaginary scenario. Every lie is a psychological maneuver to change self-object relations; the object involved may be a certain human being or a world that is spread. Every lie has its origin and finish both in the soul of the subject and its interpersonal environment. Every lie creates something and makes something. Contrary to the truth, every lie, to a greater or lesser degree, attacks, or is greater, opposes great separation, limitations, and the nature of aggression, genital differences, and incest barriers that are everywhere. The above is a description of various basic elements in lies. 


\subsection{The Types of Lies}

According to Bryant, Erin M. (2008: 23-48), lie can be divided into 3, i.e. real lies, white lies and gray lies.

\section{A. Real lies}

Real lies were defined as being "something that is not true" by both interviewees, as well as a female focus group participant. Participants used a number of different terms to describe this form of lying. While some simply called them a lie, a large number referred to them as a "real lie," a "flat out lie," a "bold-faced lie, and "a" full-blown lie" and even a "straight-up lie." Although these terms differed slightly, they all highlighted the intense nature of real lies in comparison to other forms of lying. The severity of real lies was also evident in that participants defined them as being unacceptable lies that were malicious, self-serving, complete fabrications of the truth, that hold serious consequences.

\section{- Intention}

Participants overwhelmingly agreed that a liar's intention or motivation for lying is an important factor to consider when judging a lie. Real lies were described as having malicious motives. One male focus participant defined real lies as "knowingly leading someone away from the truth" and labeled them as "manipulative." A female and a male in different focus groups both labeled real lies as being "deceptive" and "deceitful," while the male interviewee labeled them as "thought out" and "devious." All of these adjectives suggest a malicious and premeditated intention for lying. The female explained that a real lie is a "full on lie where you are either hiding the truth from somebody or you're deliberately hurting them." The common characteristic in all these descriptions is that real lies were described as being told with the purpose of misleading or hurting someone.

\section{- Consequences}

Participants also consistently claimed that the consequences of a deceptive act are important in differentiating between types of lies. According to one female participant, an important characteristic of a real lie is that "it affects a lot of people." A male participant noted that in a real lie, "the repercussions of that are like way worse" than other types of lies. The presence of serious and negative consequences was an important marker of real lies. For example, a different male stated that telling a real lie "would reduce the trust in the people telling them," so harm is caused by the act of telling a real lie. This is mirrored by a female participant who claimed that a real lie "seems to carry direct consequences." These consequences automatically elevated the status of a lie into a real lie.

\section{- Beneficiary}

The majority of participants asserted that a characterizing element of real lies was their self-serving nature. According to a male participant, "It seems like real lies benefit whoever's lying... white lies benefit someone else." A female in another focus group echoed this idea in saying that real lies are "interested in yourself and benefiting yourself" A different female categorized an example situation as a real lie because "she is doing it for her own good, not for someone else's. It is for personal reasons." These self-serving lies were described as being used to further a person's own interests, cover their own mistakes, or avoid responsibility for one's actions without regard for other people. This 
egotistical, self-interested motivation for lying surfaced as a major characteristic of real lies

\section{- Truthfulness}

Real lies were also regularly defined as being complete fabrications with no element of the truth. Participants labeled lies as being blatantly untruthful and dishonest. One female said that with a lie, "there's absolutely no truth to it." Building on that statement, a male added that "A lie could be, the whole story could be not truthful" and that that "there is zero truth to it." This complete lack of truth was a major defining factor of real lies in that the most blatantly untrue lies also tended to receive the harshest evaluations.

\section{- Acceptability}

Participants regularly highlighted the fact that real lies are never acceptable, regardless of the circumstances. For example, the male interviewee stated that real lies are "totally unacceptable no matter what the situation is." The female interviewee noted that due to their unacceptability, "You feel bad after you tell a real lie and you have a conscience with that. And with a white lie you're, you know that it is just to make someone feel a little better or something like that." The guilt associated with telling a real lie is the direct result of knowing that they are unacceptable behavior. Since they were viewed as being malicious, self-serving, complete fabrications of the truth, real lies were characterized as unacceptable behavior.

\section{B. White lies}

White Lies Participants also shared a common definition regarding a form of lying referred to as a "white lie" or "fib." According to the male interviewee, white lies are "sparing someone's emotions or feelings... if it is something trivial." The female interviewee mirrored this definition by saying that a white lie is "stretching the truth to spare feelings." Participants regularly used words such as "harmless," or "trivial" when describing white lies. The common element in all participant definitions was that white lies were said to be more common and hold more positive connotations than real lies. White lies were also described in their relation to the five differentiating factors in that they were defined as acceptable lies that are altruistic, have a benign intent, represent a partial truth and hold only trivial consequences.

\section{- Intention}

White lies were described as lacking a malicious intent or goal of purposely harming someone. In fact, white lies were clearly characterized by a benign intent. A male participant explained that telling kids that there is a Santa Claus is completely false, yet is only a white lie because it lacks a malicious intent and even aims to make people happy. A different male agreed that, "A white lie is like more pure. Just like the color white is associated with more pure things. They are not harmful to anyone, just like Santa Claus doesn't hurt a little kid to believe." The male interviewee claimed that white lies are usually used in "avoiding awkwardness in situations." Similarly, a female participant stated that white lies are often told "just trying to not get in the middle of someone else's affairs." All of these examples illustrate a benign purpose in that there is no intent to purposely trick or harm someone. 


\section{- Consequences}

White lies are also characterized as having a lack of serious consequences. For this reason, white lies were widely defined as being trivial, meaningless and harmless. One female defined white lies as "lying about something that is not important," while another female added that "a white lie is more something that is not that meaningful." One male noted that when you tell a white lie "it is like who cares" because there are no consequences. The participants almost unanimously agreed that a woman lying about liking her husband's cooking is a white lie because there were not any consequences from lying. As one male put it, "Unless he is going into a career of cooking then I do not think it is going to hurt him any to not know that his food sucks." In these examples, participants regularly emphasized that in order for a lie to be categorized as a white lie it could not have any severe consequences.

\section{- Beneficiary}

Having an artistic purpose was said to be one of the most salient characteristics of white lies. Whereas real lies were told out of self-interest, white lies were described as being told with the purpose of helping, protecting, or benefiting someone else. One female claimed telling a white lie is "lying to a person so you don't hurt someone's feelings." The female interviewee noted that you are told not to lie but you are also told not to be meaning to people. So when you are not being mean to someone you may say what the other person wants to hear instead of instead of telling exactly how it is. A male provided a similar example in claiming "it' is like when you tell a little kid in a play or something he did great, and he sucked. Just because the kid sucked you do not break his heart. You tell him he did a good job and life goes on." In all of these examples the use of a white lie was said to protect someone else's feelings from unnecessary harm or embarrassment.

\section{- Truthfulness}

Whereas real lies were said to be complete fabrications, white lies were described as being partial truths, exaggerations, or omissions. Participants explained that "a white lie could be just like tweaked details" or "bending the truth" because "white lies usually have some part of the truth in it." For example, one male focus group participant provided the example of "someone says they caught a hundred pound fish when they caught a five pounder." This was said to be a half-truth because this person really did catch a fish; they just exaggerated the details. Furthermore, given the example of a wife lying about enjoying a meal her husband cooked a different female pointed out that "It could be the truth because she could have enjoyed the fact that he went out of his way to do that. Like it is the thought that counts sort of thing." This situation was labeled a white lie because it was partially true in that she may not have enjoyed the food itself, but did appreciate his effort. It was also pointed out that since this lie is an opinion, there is no way of knowing if it was the complete truth. In this way, as suggested by a male, "I think it's possible that it is true with a white lie." Thus, the element of being partially or potentially true was continually brought up as a trademark factor of a white lie.

\section{- Acceptability}

One of the largest factors discussed by participants was the fact that white lies are generally considered to be an acceptable and in some cases, expected behavior. In fact, there was almost unanimous agreement among participants that white lies are far more acceptable than real lies. One major reason why white lies were said to be acceptable is 
that their trivial nature makes it easier for people to use them on a frequent basis. According to a male participant, "I think most people in the world.... Its universal... most people will admit that they do say white lies every once in a while." A different male added that "white lies are justifiable. Like you said, most people do them, it is okay, you can get away with it, and it does not hurt anybody." Thus, the perception that most people tell white lies made them more acceptable according to the participants.

Some participants went even further in their classification of white lies as being not only acceptable, but also expected behavior. A female participant illustrated this view in saying that white lies are more acceptable than lies because everybody tells white lies. Like if you are eating at someone's house and they ask if you like the food and you really do not, you cannot say you do not. They had been upset if you said you did not like it so they expect a white lie. They have a preconceived answer that they want. This view was confirmed by a male participant who claimed "it gets expected sometimes that you are gonna get lied to. Like sometimes you ask a question wanting one answer and when you get that answer you're happy. Even if it is completely wrong you're like, ok that is all I wanted to hear." In these situations, white lies were described both necessary and useful in that participants felt that telling people what they want to hear is the right thing to do.

Finally, people justified the acceptability of white lies in suggesting that it is acceptable to tell a white lie when telling the truth would involve getting someone else in trouble or revealing someone else's indiscretions. One male claimed "there is like a general rule though, like you do not tell on people. You let her admit it because you do not want to rat on her, and she'll get in more trouble than if you let her do it." A male in a different focus group added "it is also ingrained in society that you wouldn't rat someone else out." In both of these views, it is stressed that people are expected to plead ignorance regarding knowledge of situations that would incriminate someone else. A third male summarized that "I think sometimes you do not have the right to tell the truth... like you have to lie to them. So that I consider a white lie. It is like if you tell them the truth it is not your place." In all of the above cases, white lies are considered acceptable because they are harmless, common, expected, or involve a situation where telling the truth would reveal someone else's indiscretions.

\section{Gray lies}

The third category of lies that surfaced in this study did not have the boundaries that real lies and white lies possessed. Instead, gray lies were described as being lies that were not necessarily real lies, yet were too serious to be considered white lies. For this reason it is hard to discuss gray lies in terms of the factors used to discuss real and white lies. Instead, it is useful to examine the two types of lies that participants described as falling into the gray lies category: ambiguous gray lies, and justifiable gray lies.

Ambiguous Gray Lies. One key element discussed concerning gray lies is that not every lie can be easily put into one category and labeled a complete real lie or a complete white lie. Instead, some lies are ambiguous because they are heavily open to interpretation. In discussing this fact, a male participant noted that, "lies can differentiate. We were able to reason why it was a lie and we were also able to reason why it was a white lie. And to me that makes it a gray area if you can classify it in both." When discussing an example of an ambiguous gray lie, a female stated "it could kind of be in the gray area again because it is completely not true. But it is also helping her." The characteristics of this lie clashed with the varying factors considered. When looking at the truthfulness factor this lie seems to be a real lie, but when looking at the beneficiary 
factor, it appears to be a white lie. This ambiguity of the situation and the fact that it can be interpreted in different ways led participants to place it in the gray lie category.

Justifiable Gray Lies. The second key element dealt with acceptability, which was the major factor brought up concerning gray lies. The participants argued that some lies take the appearance of real lies in that they have consequences, are self-serving, purposely deceive someone, and are complete fabrications. However, they also argued that sometimes the use of these lies is justifiable given certain circumstances. For example, a male participant claimed that a gray lie is "a real lie that is justified. Like when you tell people I had to lie about this and everyone's like well, you had to do it... and that's like accepted." A different male confirmed that a justifiable gray lie is "a full-blown lie but it is legit." For this reason, it falls in the gray area of being a lie that is justifiable. Another male participant noted that with many gray lies "It is a lie, but it is acceptable because anyone would do it." This follows the sentiment that given the same set of circumstances most people would tell a lie. A female participant claimed that in many cases "It may like be a morally justifiable lie... but it is still a lie." The common theme that was evident is that sometimes even real lies are justified.

Most of the lies that participants placed into this category involved telling a fullblown or real lie in order to protect one's self or another from a serious harm that could arise if the truth were to surface. The example was discussed of someone lying to their boss about having done something wrong so as to avoid getting in trouble. Participants unanimously agreed that this was a real lie; however, many argued that it was justified because telling the truth would have gotten the person fired. Similarly, making up an fake excuse for having missed a test was said to be a legitimate use of a real lie because the teacher would not have accepted the truth. In this way, real lies that are commonly viewed as justifiable become gray lies.

Table 1. Categorizations of Lies according to Bryant (2008)

\begin{tabular}{|c|c|c|c|c|c|}
\hline & \multicolumn{5}{|c|}{ Factors } \\
\hline & Intention & Consequences & Beneficiary & Truthfulness & Acceptability \\
\hline Real Lies & $\begin{array}{l}\text { Malicious } \\
\text { Deliberate } \\
\text { Deceptive } \\
\text { Deceitful }\end{array}$ & $\begin{array}{c}\text { Serious } \\
\text { Direct }\end{array}$ & $\begin{array}{c}\text { Self-Serving } \\
\text { Egotistical }\end{array}$ & $\begin{array}{l}\text { Complete } \\
\text { Fabrication } \\
\text { Blatant Untruth } \\
\text { Zero Truth }\end{array}$ & $\begin{array}{l}\text { Unacceptable } \\
\text { Not Justified }\end{array}$ \\
\hline White Lies & $\begin{array}{l}\text { Benign } \\
\text { Pure }\end{array}$ & $\begin{array}{c}\text { Trivial } \\
\text { Meaningless } \\
\text { Harmless }\end{array}$ & $\begin{array}{c}\text { Altruistic } \\
\text { Other-Focused } \\
\text { Protecting } \\
\text { Helpful }\end{array}$ & $\begin{array}{l}\text { Partial Truth } \\
\text { Half Truth } \\
\text { Bending the Truth } \\
\text { Stretching } \\
\text { the Truth }\end{array}$ & $\begin{array}{l}\text { Acceptable } \\
\text { Justified } \\
\text { Expected } \\
\text { Common }\end{array}$ \\
\hline Gray Lies & & & & & \\
\hline $\begin{array}{c}\text { Ambiguous } \\
\text { Gray Lies }\end{array}$ & $\begin{array}{c}\text { Ambiguous } \\
\text { Intention }\end{array}$ & $\begin{array}{c}\text { Ambiguous } \\
\text { Consequences }\end{array}$ & $\begin{array}{l}\text { Ambiguous } \\
\text { Beneficiary }\end{array}$ & $\begin{array}{l}\text { Ambiguous } \\
\text { Level of Truth }\end{array}$ & $\begin{array}{c}\text { Open to } \\
\text { Interpretation }\end{array}$ \\
\hline $\begin{array}{l}\text { Justifiable } \\
\text { Gray Lies }\end{array}$ & Malicious & Direct & Self-Serving & $\begin{array}{l}\text { Complete } \\
\text { Fabrication }\end{array}$ & $\begin{array}{c}\text { Justified } \\
\text { Acceptable }\end{array}$ \\
\hline
\end{tabular}

\section{Research Method}

According to Ary (in Fauziah, et.al, 2018: 427) descriptive qualitative method is designed to obtain information concerning the current status of phenomena that occur naturally. The method of the data analysis in this research uses descriptive qualitative 
method. There are a number of researchers who believe and support the fact that "qualitative descriptive" is a viable and acceptable label for a qualitative research design. In other words, there will be no calculative or statically work in this study. Qualitative research method is conducted by studying the organized material in order to discover inherent facts. The fact focused in this study is one of the social diseases; that is lie. Therefore, qualitative descriptive method was appropriately applied in this research as Setiawan, Barus, and Pawiro (2017) state that in social research, qualitative descriptive method is an appropriate method as it gives detailed points of some social events.

\section{Discussion}

\subsection{Real Lies}

According to Bryant, Erin M. (2008: 23-48), real lies were defined as being "something that is not true" by both interview, as well as a female focus group participant. Participants used a number of different terms to describe this form of lying. While some simply called them a lie, a large number referred to them as a "real lie," a "flat out lie," a "bold-faced lie, and "a" full-blown lie" and even a "straight-up lie." Although these terms differed slightly, they all highlighted the intense nature of real lies in comparison to other forms of lying. The severity of real lies was also evident in that participants defined them as being unacceptable lies that were malicious, self-serving, complete fabrications of the truth, that hold serious consequences.

The following quotations prove real lies that happen in the novel:

"Steve, for example, who comes to the school on Thursdays, needs help to eat his food and could not even fetch a stick. Siobhan asked me not to say this to Steve's mother.“ (Haddon's, 2003: 6)

The quotation above shows how Steve cheated his mother by asking Siobhan to help with his lunch every Thursday.

Other evidence which show the real lies done by Christopher's father to Christopher by saying that Christopher's mother died of a heart attack:

Father said that she died of a heart attack and it wasn't expected.

(Haddon's, 2003: 27)

The quotation above shows Christopher's father lied to Christopher by saying that Christopher's mother died of a heart attack. In fact Christopher's mother did not have a heart attack and had not died.

The other real lies can be seen in the following lines:

Then I stopped reading the letter because I felt sick. Mother had not had a heart attack. Mother had not died. Mother had been alive all the time. And Father had lied about this. (Haddon's, 2003: 112)

The quotation above shows the lies committed by Christopher's father by hiding all the letters that have been sent by Christopher's mother to Christopher until finally Christopher knew it. Christopher knew that his father had lied to him.

\subsection{White Lies}

According to Bryant, Erin M. (2008 : 23-48) white lies Participants also shared a common definition regarding a form of lying referred to as a "white lie" or "fib." According to the male interview, white lies are "sparing someone's emotions or feelings... 
if it is something trivial." The female interview mirrored this definition by saying that a white lie is "stretching the truth to spare feelings." Participants regularly used words such as "harmless," or "trivial" when describing white lies. The common element in all participant definitions was that white lies were said to be more common and hold more positive connotations than real lies. White lies were also described in their relation to the five differentiating factors in that they were defined as acceptable lies that are altruistic, have a benign intent, represent a partial truth and hold only trivial consequences.

The following quotations proves white lies that happen in the novel when Christopher's father lied to Christopher by saying that he had visited Christopher's mother in the hospital and said that his mother was fine :

"He said that she had been looking OK and seemed to be getting better.

She had sent me lots of love and had my Get Well card on the table beside

her bed. Father said that she liked it very much." (Haddon's, 2003: 26)

The quotations above shows how Christopher's father lied to Christopher by saying that he had visited Christopher's mother in the hospital and said that his mother was fine. But in fact Christopher's mother was not in the hospital and her father never went to the hospital.

Christopher's father lied to Christopher for the goodness of Christopher.

Then he said, "I did it for your good, Christopher. Honestly I did. I never meant to lie. I just thought... I just thought it was better if you didn't know... that... that... I didn't mean to... I was going to show them to you when you were older." (Haddon's, 2003: 114)

The quotation shows that Christopher's father, never meant to be lie but he still lie although for the good of Christopher.

\subsection{Gray Lies}

According to Bryant, Erin M. (2008: 23-48) the third category of lies that surfaced in this study did not have the boundaries that real lies and white lies possessed. Instead, gray lies were described as being lies that were not necessarily real lies, yet were too serious to be considered white lies. For this reason it is hard to discuss gray lies in terms of the factors used to discuss real and white lies. Instead, it is useful to examine the two types of lies that participants described as falling into the gray lies category: ambiguous gray lies, and justifiable gray lies. The following quotations proves gray lies that happen in the novel:

"For example, this morning for breakfast I had Ready Bred and some hot raspberry milk shake. But if I say that I actually had Shredded and a mug of tea I start thinking about Coco Pops and lemonade and porridge and Do Pepper and how I wasn't eating my breakfast in Egypt and there wasn't a rhinoceros in the room and Father wasn't wearing a diving suit and so on and even writing this makes me feel shaky and scared, like I do when I'm standing on the top of a very tall building and there are thousands of houses and cars and people below me and my head is so full of all these things that I'm afraid that I'm going to forget to stand up straight and hang on to the rail and I'm going to fall over and be killed.

This is another reason why I don't like proper novels, because they are lies about things which didn't happen and they make me feel shaky and scared. 
And this is why everything I have written here is true. (Haddon's, 2003: 19-20)

It can be concluded from the above quote, from that Christopher lie to himself. In fact he is already had a breakfast menu in that morning but he also had other breakfast options.

Father said that he didn't know what kind of heart attack she had and now wasn't the moment to be asking questions like that. (Haddon's, 2003: 27)

The quotation shows that Christopher kept asking what kind of heart attack struck his mother and his father cannot answer because he has lies.

\section{Conclusion}

Some conclusions can be drawn up from this research. The types of lie are real lies, white lies, and grey lies. Lie will only bring bad impacts to one or both parties. Real lies often occur from the behavior which seems common by the various cultures, ages, setting and more. Lie also seems to be associated with several societal problems, in often disrupts social relationship, causes problems in the work of place and corrupts politics. In the sense, a consideration of environmental factors that leads to the development and persistence of lying is by passed, as the problem of lying is assumed to reside within the individual.

\section{References}

Bryant, Erin M. (2008). Real Lies, White Lies and Gray Lies: a Typology of Deception. Kaleidoscope: A Graduate Journal of Qualitative Communication Research, 7, 23-48.

Fauziah, Raja, et.al. (2018). Adultery in Mochtar Lubis' Novel Senja di Jakarta. aicll.sastra.uisu.ac.id/index.php/aicll/article/download/54/58. (July 2019)

Fryling, Mitch J. (2016). A Developmental-Behavioral Analysis of Lying. International Journal of Psychology and Psychological Therapy, 2016, 16, 1, 13-22

James, Edwin Mahon. (2008) Definitions of Lying. https://www.academia.edu

Kenneth, Rexroth. (1998). Literature. https://www.britannica.com/art/literature/Literarycomposition

Lemma, A. (2005). The many faces of lying. International Journal of Psychoanalysis 86: $737-753$.

Patton, M. Q. (2002). Qualitative research and evaluation methods (3rd ed.). Thousand Oaks, CA: Sage

Setiawan, Muarif, Barus, Efendi, and Pawiro, Mhd. Ali. (2017). Cause and effect of suffering in Sydney Sheldon's "If Tomorrow Comes". Language Literacy: Journal of Linguistics, Literature, and Language Teaching. Volume 1, Number 1, Desember 2017, Pages: 73-96 https://doi.org/10.30743/1l.v1i1.247

Stanton, A. H. (1978). Personality disorders. In: The Harvard Guide to Modern Psychiatry, ed. A.M. Nicoli, pp. 283-295. Cambridge, MA: Belknap Press.

William, Emma J. et.al. (2013). Telling Lies: The Irrepressible Truth? PLoS ONE 8(4): e60713. doi:10.1371/journal.pone.0060713 